\title{
Clinical Profile of Patients With Severe Anaphylaxis Hospitalized in the Spanish Hospital System: 1997-2011
}

\author{
Nieto-Nieto $A^{1,2}$, Tejedor-Alonso MA ${ }^{1,3}$, Farias-Aquino E1,2, Moro-Moro $\mathrm{M}^{1}$, \\ Rosado Ingelmo $A^{1}$, Gonzalez-Moreno $A^{1}$, Gil de Miguel $A^{4}$
}

\author{
'Allergy Unit, Hospital Universitario Fundación Alcorcón, Alcorcón, Spain \\ ${ }^{2}$ International Doctoral School, Universidad Rey Juan Carlos, Alcorcón, Spain \\ ${ }^{3}$ Medicine Department, Universidad Rey Juan Carlos, Alcorcón, Spain \\ ${ }^{4}$ Preventive Medicine and Public Health Area, Universidad Rey Juan Carlos, Alcorcón, Spain
}

J Investig Allergol Clin Immunol 2017; Vol. 27(2): 111-126

doi: 10.18176/jiaci.0146

\begin{abstract}
Background: Studies assessing the severity of anaphylaxis lack a comprehensive approach to collecting data on comorbidities that may worsen prognosis.

Objective: Using the Elixhauser score (a systematic index associated with longer stay, hospital charges, and mortality), we determined which comorbidities were associated with more severe anaphylaxis.

Methods: We based our study on the Spanish Ministry of Health database of hospital discharges in Spain between 1997 and 2011. We constructed logistic regression models in which the dependent variables were outcomes related to greater severity (death, cardiac arrest, need for invasive mechanical ventilation or vasopressor drugs, admission to the intensive care unit, and length of stay) and the independent variables were the 30 comorbidities that comprise the Elixhauser score, age, sex, and main causes of anaphylaxis.

Results: We found that a higher risk of severe anaphylaxis was associated ( 3 or more logistic regressions) with age $>50$ years or having experienced cardiac arrhythmia, coagulation disorder, associated fluid-electrolyte imbalance, chronic pulmonary disease, or Echinococcus anaphylaxis. Likewise, in the adjusted analysis, a higher Elixhauser score was associated with most of the outcomes analyzed for severity of anaphylaxis.

Conclusions: Cardiovascular and respiratory diseases increase the severity of anaphylaxis, and the resulting poor health status (represented as a higher Elixhauser score) is associated with more severe anaphylaxis.

Key words: Severity. Anaphylaxis. Comorbidities. Elixhauser score. Cardiovascular. Respiratory. Diseases.
\end{abstract}

\section{Resumen}

Antecedentes: Los estudios que recogen datos sobre comorbilidades que empeoran la gravedad de la anafilaxia, carecen de un acercamiento exhaustivo.

Objetivo: Usando la puntuación de Elixhauser (un sistema de puntuación asociado con mayor estancia hospitalaria, mayor gasto hospitalario y muerte), establecimos que comorbilidades fueron asociadas con anafilaxia grave.

Métodos: Usamos para el estudio la base de datos de altas hospitalarias del Ministerio Español de Sanidad, entre 1997 a 2011. Se obtuvo varios modelos de regresión logística, en las cuales las variables dependientes fueron desenlaces relacionados con eventos asociados habitualmente a una gran gravedad de los episodios (muerte, parada cardio-respiratoria, necesidad de uso de ventilación mecánica invasiva o medicamentos vaso-presores, ingreso en la Unidad de Cuidados Intensivos y duración de la estancia) y las variables independientes fueron las 30 comorbilidades que comprenden la puntuación Elixhauser, junto con edad, sexo y las grandes causas de anafilaxia. Resultados: Encontramos que un mayor riesgo para anafilaxia grave estuvo asociado (3 o más regresiones logísticas con significación estadística) con una edad de más de 50 años, o haber experimentado arritmias cardiacas, alteraciones de la coagulación, disbalance hidro-electrolítico, enfermedad pulmonar crónica o anafilaxia por Echinococcus. Así mismo, en un análisis ajustado, una puntuación mayor del sistema Elixhauser se asoció con la mayoría de las variables de desenlace usadas para analizar la gravedad de la anafilaxia.

Conclusiones: Enfermedades cardio-vasculares y respiratorias incrementan la gravedad de la anafilaxia y un mal estado de salud (representado por mayores puntuaciones del Sistema de puntuación de Elixhauser) se asocian con mayor gravedad de la anafilaxia.

Palabras clave: Gravedad. Anafilaxia. Comorbilidades. Puntuación Elixhauser. Cardio-vascular. Respiratorias. Enfermedades. 


\section{Introduction}

The severity of anaphylaxis can be classed as moderate (dyspnea, stridor, wheeze, vomiting, dizziness, chest or throat tightness, and abdominal pain), very severe (hypoxia, hypotension, and neurologic involvement) [1], and fatal [2-4]. The classic risk factors for more severe anaphylaxis are older age, cardiovascular and respiratory disease, antihypertensive drugs (principally ß-blockers and ACE inhibitors), drugs, venom, and uncontrolled asthma [4-10].

Publications on the risk factors associated with the most severe presentations of anaphylaxis focus only partially on specific factors (eg, the importance of respiratory disease) [9], results are inconsistent (eg, aggravation of anaphylaxis by ß-blockers, differences with respect to the most severe type of anaphylaxis) [5-8], or the principal outcome measures are different (eg, admissions for anaphylaxis, need for mechanical ventilation) [4-10].

We studied a cohort of patients with anaphylaxis admitted to hospitals of the Spanish National Health System from 1997 to 2011 to evaluate the risk factors associated with poor outcome. Our comprehensive approach was based on the severe chronic comorbidities in the Elixhauser score [11]. The score uses 30 different comorbidities from different groups of diseases, as follows: cardiovascular system (6), neurologic diseases (2), pulmonary diseases (1), endocrine and nutritional diseases (5), kidney failure (1), digestive diseases (2), HIV infection (1), cancer (3), connective tissue diseases (1), hematologic diseases (3), fluid-electrolyte imbalance (1), substance abuse (2), and psychiatric diseases (2). In addition, comorbidities associated with the principal diagnosis of an admission and acute comorbidities (pneumonia, pleural effusion, urinary tract infection, cardiac arrest, cardiogenic shock, and respiratory failure) are excluded. The Elixhauser score has been found to be significantly associated with substantial increases in length of stay, hospital charges, and mortality both for heterogeneous and for homogeneous disease groups [11].

\section{Methods}

\section{Design and Selection of Cases}

The study was carried out using the Spanish Minimum Basic Data Set (MBDS), which is a database created by the Spanish Ministry of Health to collect standardized information on hospital discharges in Spain. The database uses the codes of the Spanish version of the International Classification of Diseases, Ninth Revision, Clinical Modification (ICD-9$C M)$ [12] and covers 98\% of public hospitals in Spain and many private hospitals [12]. The study was performed using data from the MBDS between 1997 and 2011.

We chose a retrospective observational cohort design. Possible cases of anaphylaxis were based only on the principal diagnosis: thus, the most probable cause of admission was an anaphylaxis episode, and the remaining diagnoses were the comorbidities, which could worsen the anaphylaxis episode. Using all discharge diagnoses to identify anaphylaxis meant that comorbidities could have been associated with an admission diagnosis other than anaphylaxis. We used 2 strategies to select cases of anaphylaxis, as described elsewhere (Table 1). First, we chose $I C D-9-C M$ codes that were specifically associated with anaphylaxis and causes of anaphylaxis. In addition, following a strategy adapted from Harduar-Murano et al [13], we used codes related to the causes of anaphylaxis and symptoms or signs of organs or systems whose combination led us to select episodes that fulfilled the criteria for the definition of anaphylaxis of the NIAID-FAAN Symposium (National Institute of Allergy and Infectious Disease/Food Allergy and Anaphylaxis Network) [14] (Table 1).

We assessed the severity of anaphylaxis episodes using $I C D-9-C M$ codes related to infusion of vasopressor drugs (00.17), invasive mechanical ventilation (96.70 to 96.72), and cardiorespiratory arrest (427.5). We also considered death, admission to the intensive care unit, and length of stay. Likewise, the comorbidities studied were chosen from the list of comorbidities used to calculate the Elixhauser score $[11,15]$, and the ICD-9-CM codes that represent them were those proposed by the Agency for Healthcare Research and Quality (version 3.5) [16].

This study was approved by the Ethics Committee for Medical Research of Hospital Universitario Fundación Alcorcón (number 16/05).

\section{Statistical Analysis}

Given the nonparametric distribution of the variables, values are expressed as the mean, median, and interquartile range.

We constructed several logistic regression models (binomial and ordered according to the type of variable), where the dependent variable was the indicator of severity and the covariates the comorbidities comprising the Elixhauser score [11], major causes of anaphylaxis, sex, and age group. We used a modified version of the Elixhauser score [15] and not its individual diseases as the covariate in another cluster of logistic regression models adjusted for cardiac and respiratory diseases, cause of anaphylaxis, sex, and age in order to ascertain whether comorbidities other than cardiac and respiratory diseases increase the severity of anaphylaxis.

We calculated $\mathrm{C}$ statistics to assess the discriminatory power of each model [17] and measured the calibration of the models using the Hosmer-Lemeshow goodness-of-fit test $[15,18]$.

The Elixhauser score was originally designed for discharged patients $\geq 18$ years. However, given that our study population comprised patients of all ages, we assessed the discriminatory power of this score in patients older and younger than 18 years for the various outcomes of the study. We also carried out a factor analysis to assess the homogeneity of variables associated with severity and the underlying structure of the data.

The power of the study varied with the number of positive results for each independent variable studied: for variables with only 100 cases or similar, with a type I $\alpha$ error of 0.05 , the study had a power close to or higher than $80 \%$ if the odds ratios were at least 1.75 and the risk factor studied appeared in at least in $20 \%$ of the controls. Such was the 
Table 1. ICD-9-CM Codes Used to Select Admissions for Anaphylaxis

\begin{tabular}{ll}
\hline ICD-9-CM Code & Description of ICD-9-CM Code \\
\hline & SPECIFIC CODES FOR ANAPHYLAXIS AND FOR CAUSES OF ANAPHYLAXIS \\
\hline 122 & Echinococcosis \\
127.1 & Anisakiasis \\
989.5 & Venom \\
989.82 & Toxic effect of latex \\
478.6 or 478.25 & Laryngeal or naso-pharyngeal edema \\
995.6 & Anaphylactic shock due to adverse food reaction \\
995.7 & Other adverse food reactions, not otherwise classified \\
995.0 & Unspecified anaphylactic shock \\
995.1 & Angioneurotic edema \\
995.2 & An unspecified adverse effect caused by the correct administration of a drug or medicinal or biologic \\
995.3 & substance \\
999.4 & Unspecified allergic reactions \\
995.4 & Anaphylactic shock due to serum \\
E905 & Shock due to anesthetic drugs \\
E930 to E949 & Venomous animals and plants as the cause of poisoning and toxic reactions \\
& Drugs and biologic substances which cause adverse effects when used as therapy
\end{tabular}

SIGNS AND SYMPTOMS INCLUDED IN THE DEFINITION OF ANAPHYLAXIS OF THE NIAID-FAAN CONSENSUS

Respiratory Involvement

\begin{tabular}{|c|c|}
\hline 518.81 & Acute respiratory episode \\
\hline 518.82 & Other respiratory insufficiency, not otherwise classified concepts \\
\hline 786.00 to 786.09 & Dyspnea and respiratory alterations \\
\hline 786.1 & Stridor \\
\hline 493.0 & Extrinsic asthma \\
\hline 493.9 & Unspecified asthma \\
\hline 493.8 & Other types of asthma \\
\hline 477.0 to 477.9 & Allergic rhinitis \\
\hline & Decreased Arterial Tension \\
\hline $458,458.0,458.2,458.8,458.9$ & Hypotension \\
\hline & Gastrointestinal Involvement \\
\hline 558.3 & Allergic gastroenteritis or colitis \\
\hline $787.0^{*}$ & Nausea or vomiting \\
\hline 787.4 & Visible peristalsis \\
\hline 787.5 & Abnormal bowel sounds \\
\hline 787.6 & Fecal incontinence \\
\hline 789.0 & Abdominal pain \\
\hline & Mucosa and Skin Involvement \\
\hline 2.73 & Conjunctival edema \\
\hline 374.82 & Eyelid edema \\
\hline 478.6 & Laryngeal edema \\
\hline 478.25 & Nasopharyngeal or pharyngeal edema \\
\hline 782.62 & Flush \\
\hline 708 & Urticaria \\
\hline $698.1,698.8,698.9$ & Pruritus \\
\hline
\end{tabular}

Abbreviations: ICD-9-CM, International Classification of Diseases, Ninth Revision, Clinical Modification; NIAID-FAAN, National Institute of Allergy and Infectious Disease and the Food Allergy and Anaphylaxis Network.

case for cardiac arrest, discharge from the intensive care unit, and administration of vasopressor drugs. In the case of independent variables, again with a type I $\alpha$ error of 0.05 , a population of 300-400 cases (for example, patients undergoing invasive mechanical ventilation and patients with the longest stays in the hospital) gave a power of $80 \%$ or nearly $80 \%$ when the odds ratios were 1.5 and the risk factor studied appeared in at least $20 \%$ of the controls. 


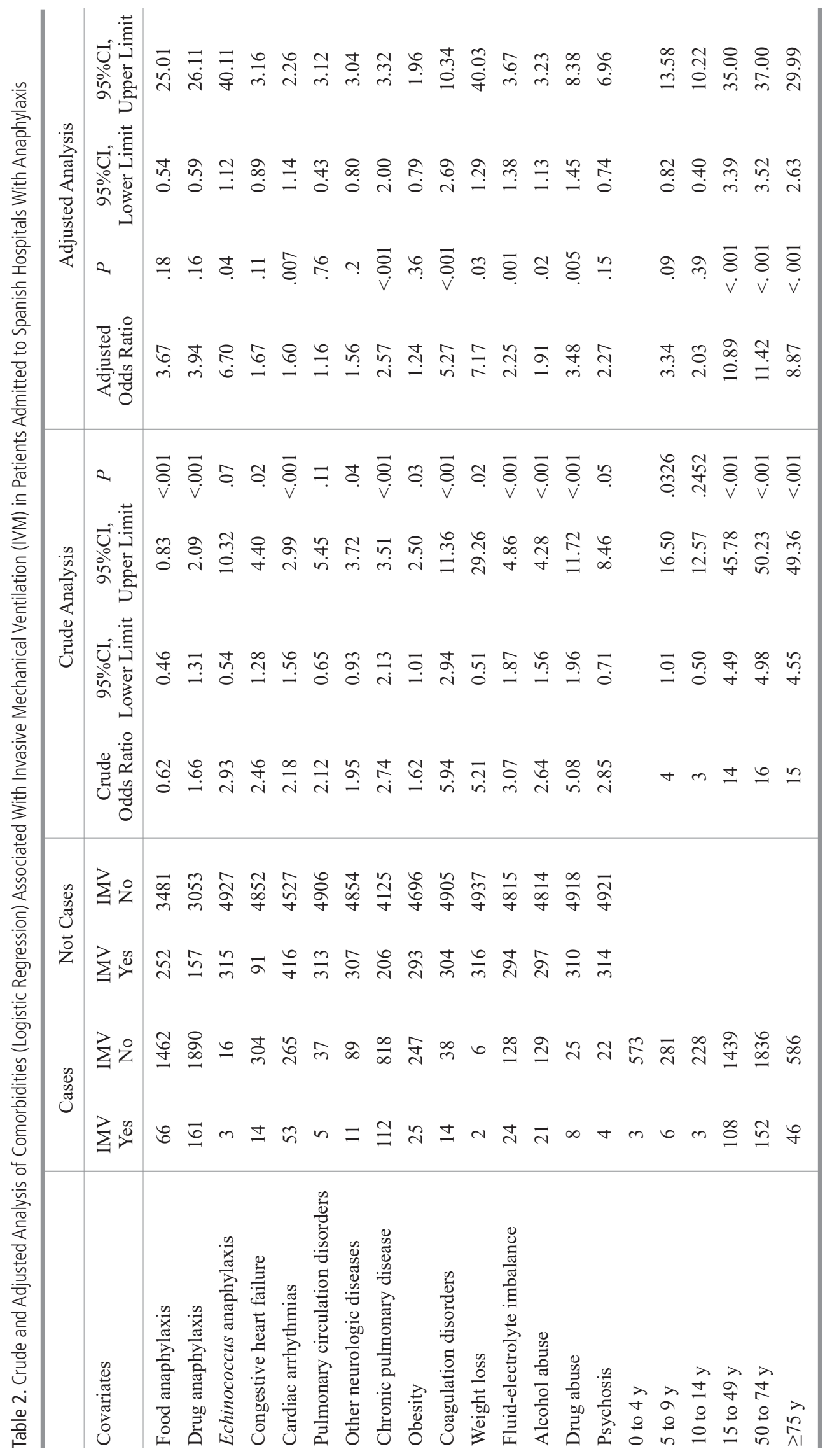




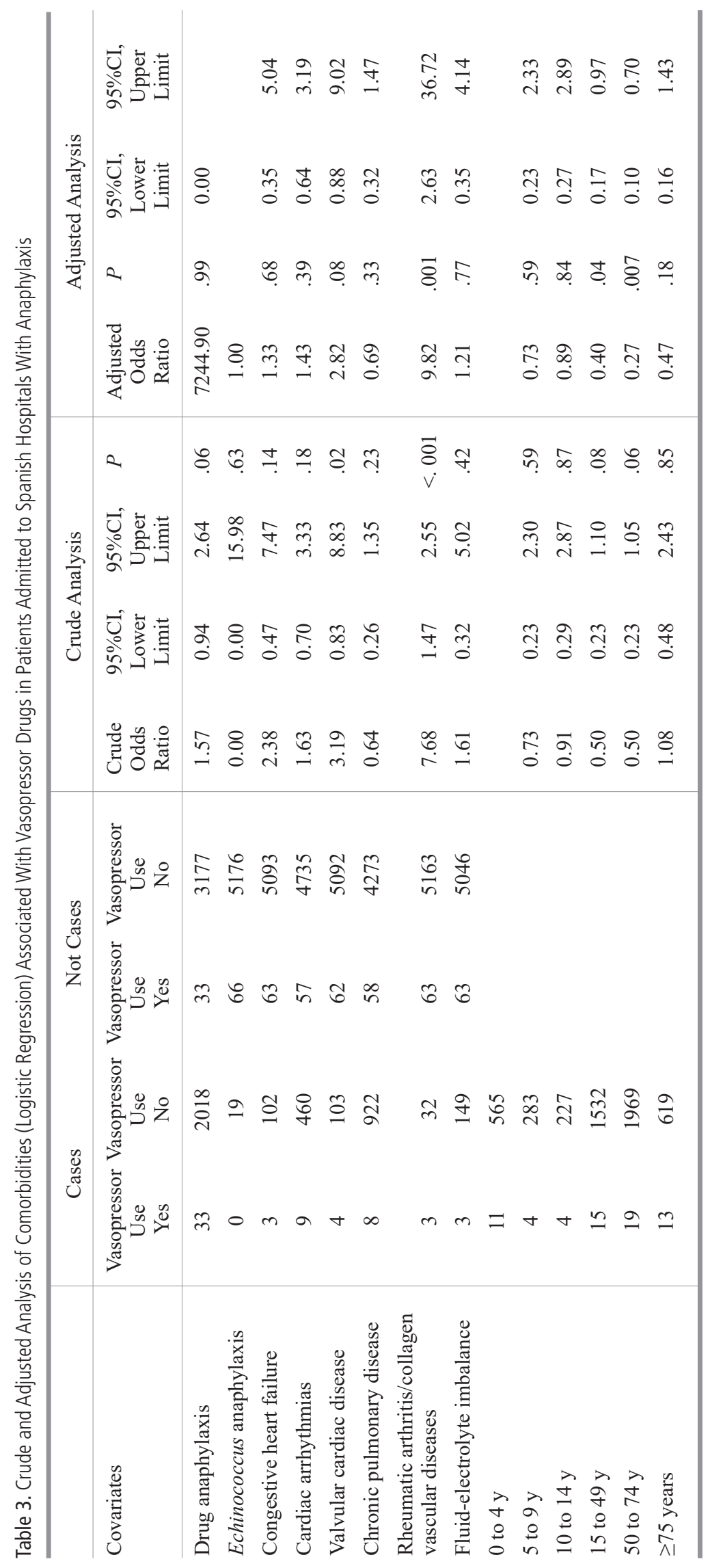




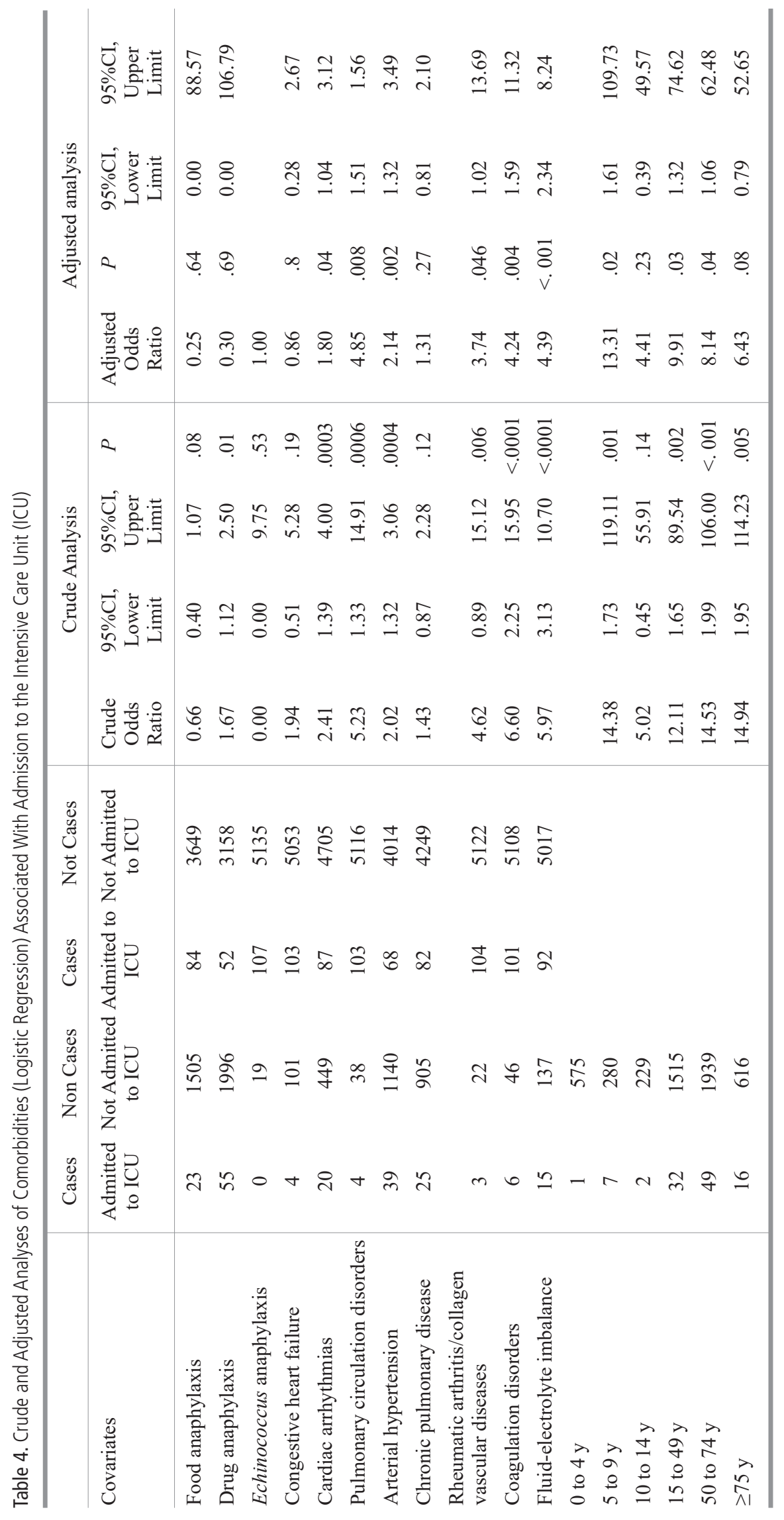




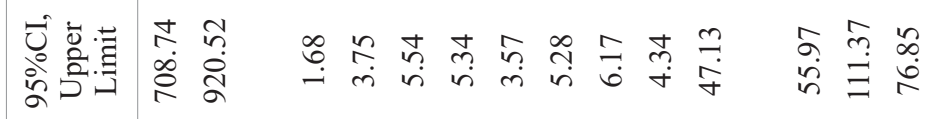

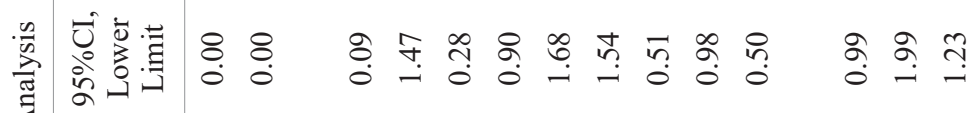

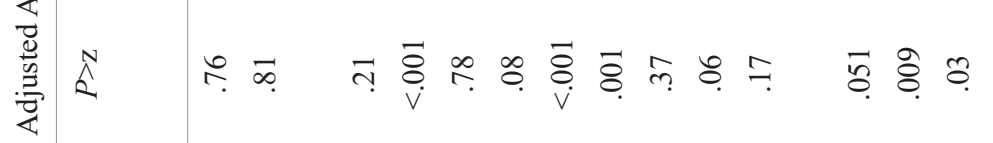

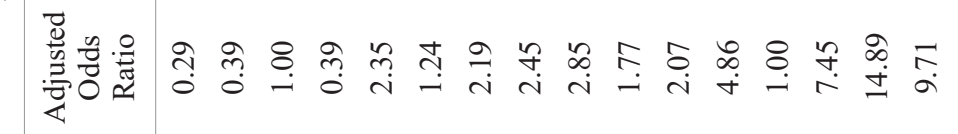

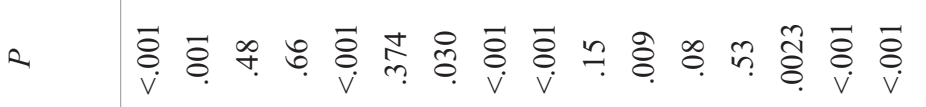

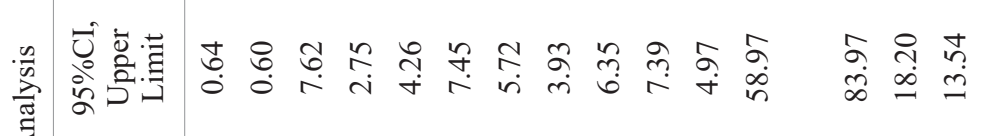

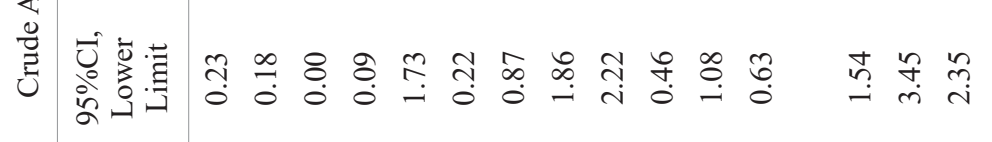

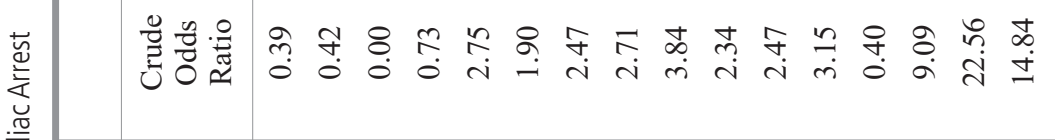

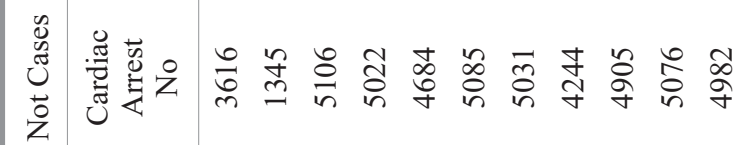

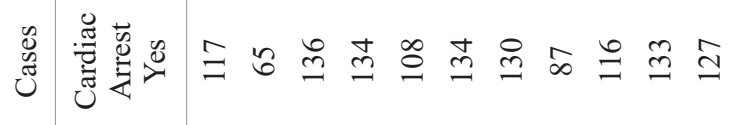

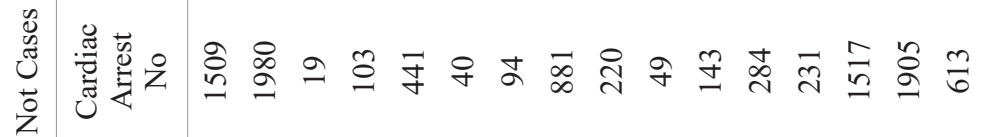

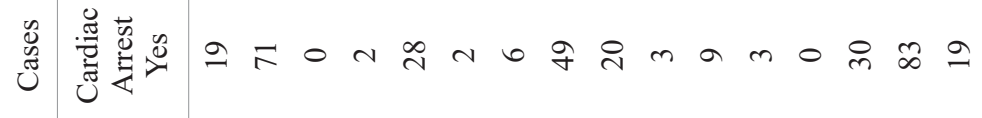

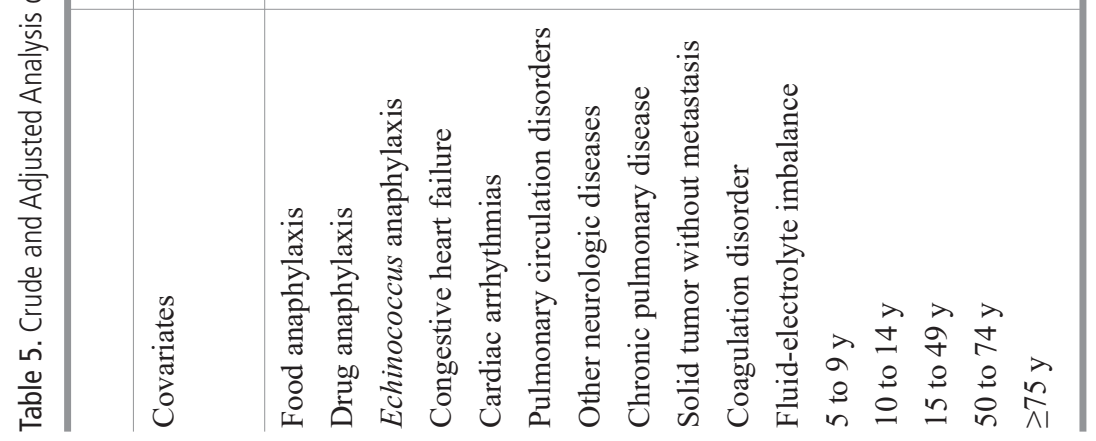




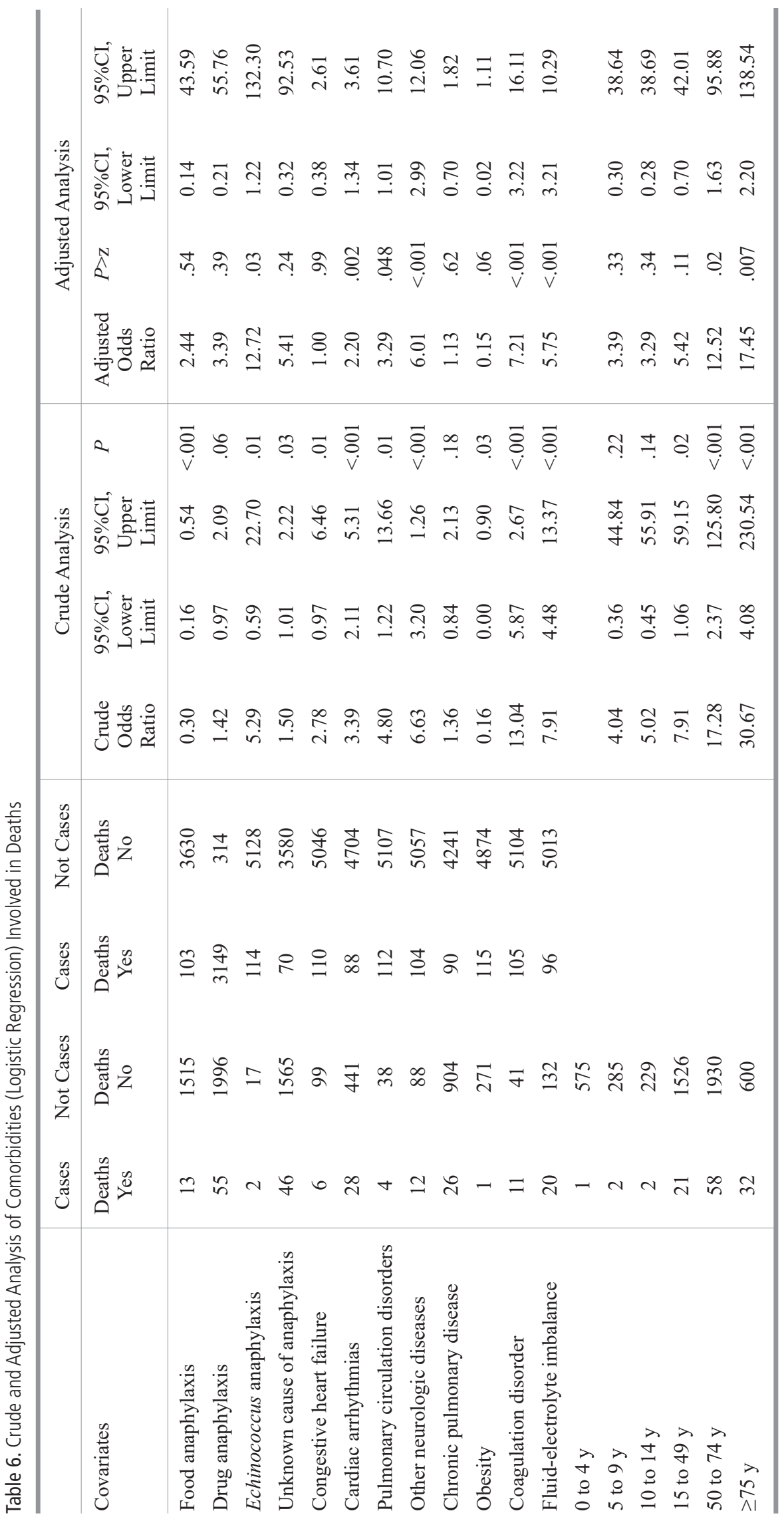




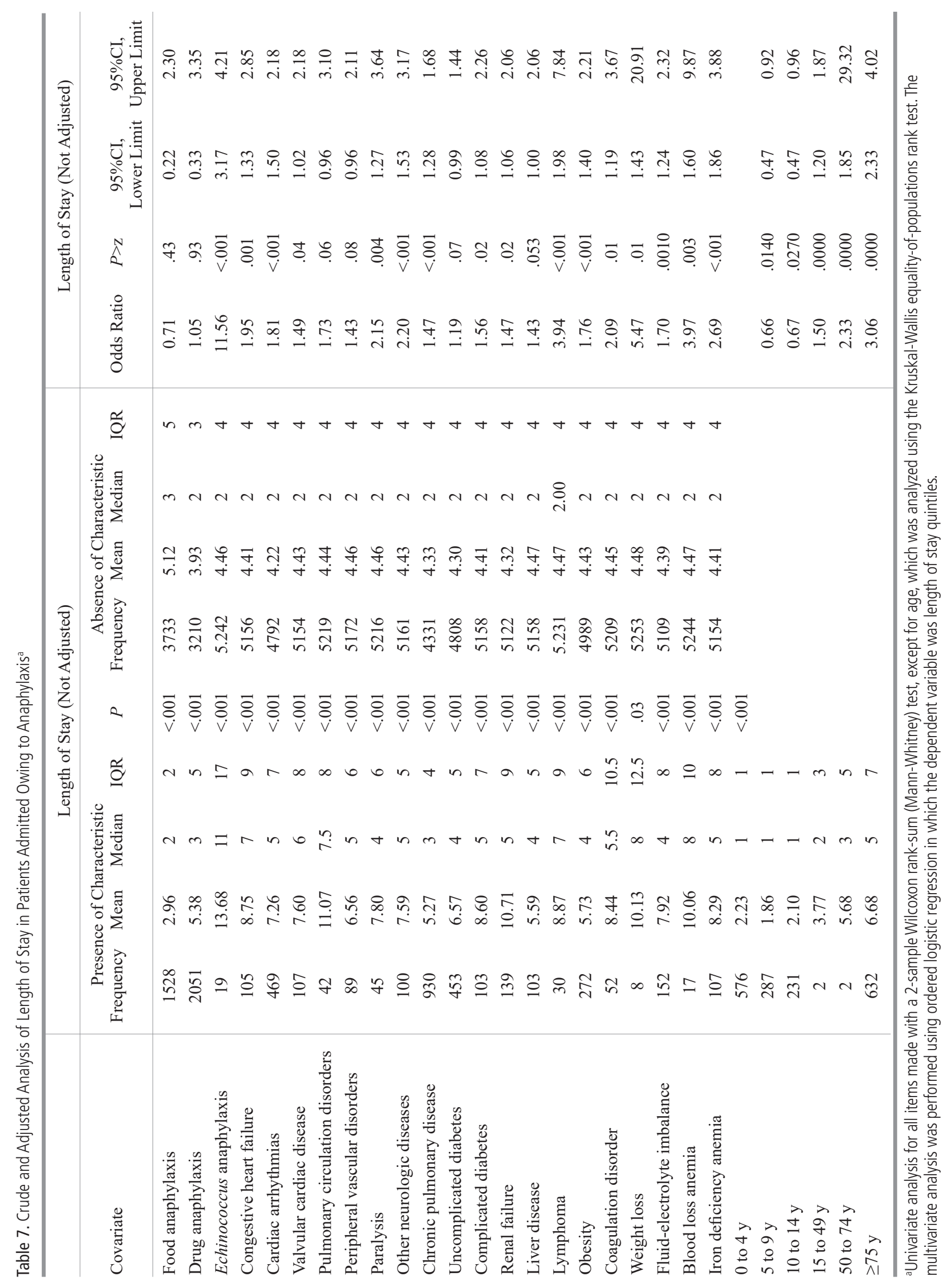




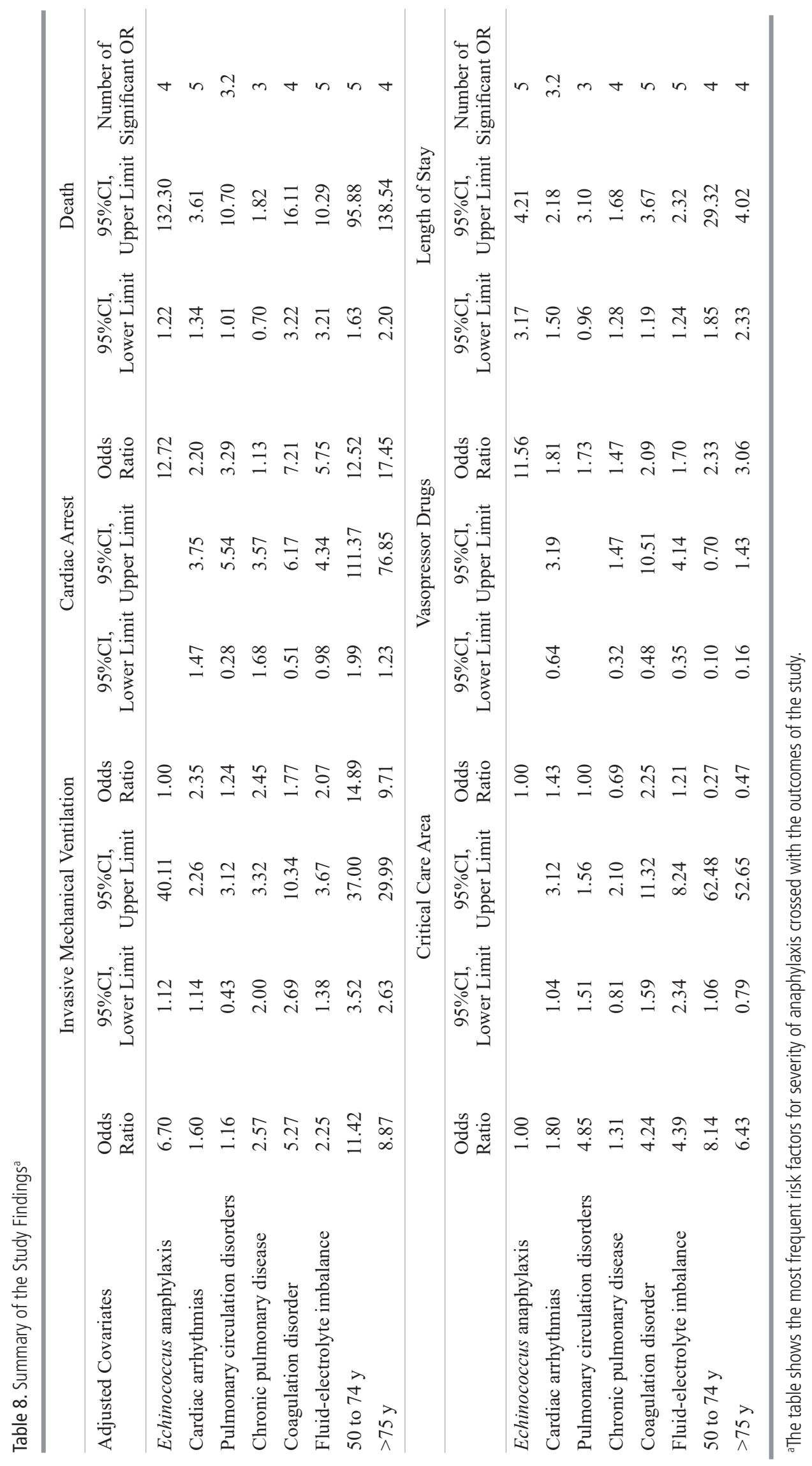




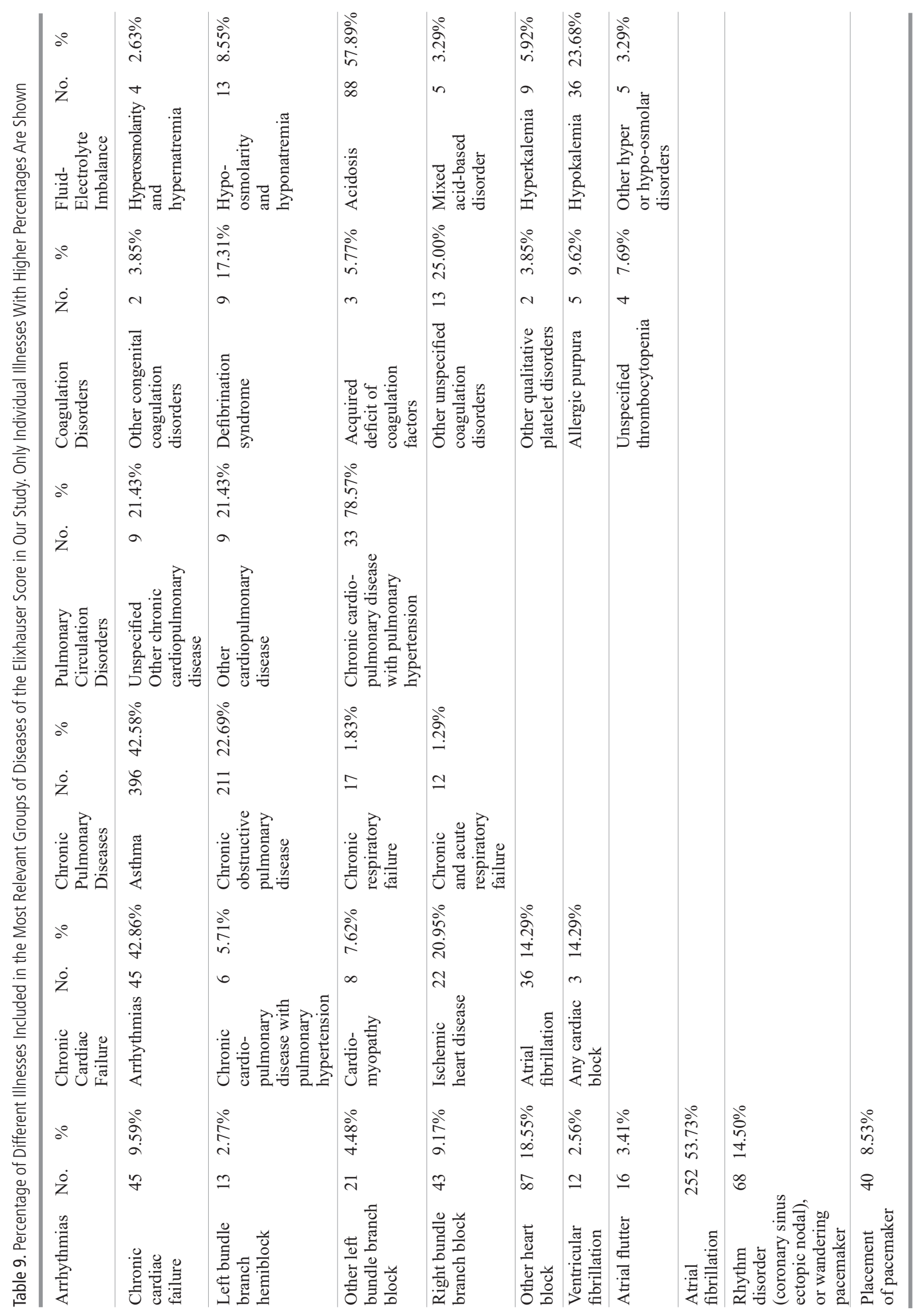




\section{Results}

Based on the aforementioned criteria for the study period (1997 to 2011), we identified 5261 admissions in which the principal diagnosis was anaphylaxis. Of these, $53.75 \%$ involved males, with a median (IQR) age of 49 years ( 43 years).

Tables 2 to 7 show the crude and adjusted analyses. In general, patients with a specific characteristic (eg, use of invasive mechanical ventilation, vasopressor drugs) tended to have more comorbidities (cardiovascular, respiratory, and other diseases) in the corresponding crude analysis.

In the analysis of therapeutic management as proxies of a severe episode of anaphylaxis, admission to the intensive care unit and need for invasive mechanical ventilation (Tables 2 and 4) were more frequent in patients aged $>15$ years. Vasopressor drugs (Table 3) were used less frequently by patients aged 15 to 74 years. However, higher comorbidity was observed mainly in patients who needed mechanical ventilation. These patients more frequently had arrhythmias, chronic respiratory disease, coagulation disorders, weight loss and fluid-electrolyte imbalance. Invasive mechanical ventilation was more likely in Echinococcus anaphylaxis (Table 2). In patients admitted to the intensive care unit (Table 4), the most likely conditions were arrhythmias, arterial hypertension, pulmonary circulation disorders, coagulation disorders, and fluid-electrolyte imbalance. The C-statistic for the 3 items was 0.70 to 0.73 , with good calibration for the 3 items ( $P=.59$ for mechanical ventilation, $P=.45$ for admission to the intensive care unit, and $P=.34$ for use of vasopressor drugs).

Associated conditions were less common in the case of cardiac arrest and death due to anaphylaxis (Tables 5 and 6). Arrhythmias and age older than 50 years were common risk factors for cardiac arrest or death. In the case of cardiac arrest, other associated risk factors included chronic pulmonary diseases and age 15 to 49 years (Table 5). On the other hand, pulmonary circulatory disorders, coagulation disorders, and fluid-electrolyte imbalance were associated with a higher risk of death from anaphylaxis (Table 6). Likewise, the risk of death from Echinococcus anaphylaxis was higher than the risk of death from the remaining causes of anaphylaxis. For both outcomes, the $\mathrm{C}$-statistic was higher than the remaining outcomes in this study (cardiac arrest, 0.77 [95\% CI, 0.750.77]; death, 0.82 [95\% CI, 0.80-0.83]). Good calibration was noted for cardiac arrest $(P=.59)$, but not for death $(P=.03)$.

Finally, we found that many comorbidities were associated with longer stay, namely, heart diseases (including congestive heart failure) and pulmonary disorders (chronic pulmonary diseases, pulmonary circulation disorders [in this case the difference was almost significant]) (Table 7). Finally, patients with anaphylaxis due to Echinococcus had longer stays than all other patients admitted with anaphylaxis

Table 8 summarizes the odds ratios of the main risk factors for severity of anaphylaxis crossed with the outcomes of the study.

\section{Sensitivity Study}

We found that discrimination was almost always better in patients aged $<18$ years than in older patients and in the total group, except for length of stay, where the discrimination of the model was better for the whole group (data not shown).

\section{Study of Comorbidities Other Than Respiratory and Cardiovascular Diseases}

In the adjusted logistic regression models, the Elixhauser score modified by van Walraven [15] increased severity of anaphylaxis, as ascertained using the outcomes investigated in this study (mechanical ventilation, OR, 1.02 [95\% CI, 0.991.05]; cardiac arrest, OR, 1.07 [95\%CI, 1.03-1.15]; death, OR, 1.10 [95\%CI, 1.06-1.14]; admission to the intensive care unit, OR, 1.06 [95\%CI, 1.02-1.10]; vasopressor drugs, OR, 1.06 [95\%CI, 1.00-1.03]; and length of stay [quintiles] OR, 1.02 [95\%CI, 1.00-1.05]).

\section{Frequency of IIInesses From the Code Groups That Are Commonly Considered Risk Factors for Severe Anaphylaxis}

Finally, in the group of comorbidities with a $\geq 3$-fold greater statistical significance in the logistic regression models (arrhythmias, fluid-electrolyte imbalance, coagulation disorders, chronic pulmonary diseases, and pulmonary circulation disorders [in which the difference in length of stay was almost statistically significant]), we assessed the frequency of the various diseases belonging to each of the groups. The results are shown in Table 9.

In the case of arrhythmias, $9.6 \%$ of patients had chronic heart failure. In the case of chronic heart failure, $42.8 \%$ of patients had arrhythmias. Arrhythmias and congestive heart failure had different distributions $(P<.001)$.

When we analyzed asthma and chronic obstructive pulmonary disease (COPD) after adjustment for age, gender, and the remaining diseases in the Elixhauser score, we found that both were associated with invasive mechanical ventilation (asthma, OR, 2.23; 95\%CI, 1.55-3.22; COPD, OR, 1.58; 95\%CI, 1.13-2.19), whereas only COPD was associated with cardiac arrest (OR, 2.00; 95\%CI, 1.26-3.19), and longer stay (quintiles) (OR, 1.33; 95\%CI, 1.11-1.59).

\section{Correlation Between Outcomes}

We analyzed correlations between the dependent variables. Factor analysis revealed 3 components that accounted for $20 \%$ of variance. Almost all variables were involved in the first component, except the use of vasopressor drugs. This component can be interpreted as the component related to severity of anaphylaxis. The second component was length of stay, and the third component use of vasopressor drugs by patients with less severe conditions.

\section{Discussion}

Based on the registry of patients admitted to the Spanish Hospital System between 1997 and 2011 and various indicators of severe anaphylaxis, we found that a higher risk of severe anaphylaxis was associated ( $\geq 3$ logistic regressions) with age $>50$ years, history of cardiac arrhythmia, coagulation disorders, fluid-electrolyte imbalance, chronic pulmonary 
disease, anaphylaxis caused by Echinococcus, and pulmonary circulation disorders (in this case the difference in length of stay was almost statistically significant).

We chose the illnesses listed in the Elixhauser score [11] to create a comprehensive list of diseases that would enable us to assess whether comorbidities other than cardiac and respiratory diseases increased the severity of anaphylaxis. In our study, comorbidity was defined according to Elixhauser et al [11] "as a clinical condition that exists before a patient's admission to the hospital and is not related to the main reason for the hospitalization". For these authors, the first part of this definition is very difficult to confirm using clinicaladministrative data, although the second part can be readily confirmed using administrative data.

The Elixhauser Score was validated in patients aged $>18$ years. However, in our study, almost $21 \%$ of admissions due to anaphylaxis involved patients aged $<14$ years. Although the Elixhauser score has also been used in the pediatric population $[19,20]$, we performed a sensitivity analysis to ascertain the behavior of the logistic regression models of the different outcomes analyzed in patients older and younger than 18 years. Using the $\mathrm{C}$ statistic, we found that discrimination was better in patients aged $<18$ years than in patients aged $>18$ years and in the total group, except for length of stay.

For each group of diseases, when the probability of a specific outcome was high, the individual diseases were analyzed with the objective of determining whether the patient was more likely to have the comorbid condition before the episode of anaphylaxis or whether the comorbid condition developed during admission.

Cardiovascular diseases have traditionally been associated with a poorer clinical course of anaphylaxis. The presence of mast cells in the heart and the release of cardiotoxic mediators such as histamine, LTC4, and platelet-activating factor [21], as well as the increase in mast cell counts in the coronary vessels of patients with ischemic heart disease, can render the heart incapable of overcoming the systemic and cardiac effects of anaphylaxis. In addition, the widespread concomitant use of $\beta$-blockers and ACE inhibitors in cardiovascular diseases $[22,23]$ has been considered to cause more severe anaphylaxis in patients with heart disease [24]. Our literature review $[5,6,24,25]$ revealed that several markers can be used to assess the severity of anaphylaxis and that not all markers of cardiovascular disease are associated with all severity markers.

The relationship between anaphylaxis and ischemic heart disease has been studied in depth [27]. However, based on our data, a logistic regression model adjusted for other cardiac comorbidities (cardiovascular diseases, diabetes, and respiratory, liver, and kidney diseases) showed that ischemic heart disease did not increase the probability of more severe anaphylaxis, using all the outcomes of our study as proxies of severity (data not shown). In addition, we found 12 cases of Prinzmetal angina or coronary vasospasm among all cases of anaphylaxis. These cases can be considered possible cases of Kounis syndrome. All cases had an associated diagnosis of ischemic heart disease, chronic heart failure, or arrhythmias. No patients died. One patient experienced cardiac arrest, and twothirds were in the fourth and fifth quintiles for length of stay.
Arrhythmias were a significant variable in all of the severity outcomes analyzed, except for use of vasopressor drugs. Arrhythmias are associated with a worse course of anaphylaxis owing to mechanisms other than those involved in congestive heart failure, since the distribution of both variables differed. The appearance of heart block and arrhythmias may be related to myocardial hypoxia during anaphylaxis $[24,26]$ or local secretion of noradrenaline from sympathetic nerve endings resulting from secretion of renin from mast cells and activation of the renin-angiotensin system [21]. The evidence presented above suggests that arrhythmias follow the onset of anaphylaxis.

We also found that chronic cardiopulmonary disorders with pulmonary hypertension were present in most of the $90 \%$ of cases of pulmonary circulation disorder, which in the adjusted multivariate analysis generated higher percentages of deaths, admissions to the intensive care unit, and longer hospital stays (in this case almost significant). The long progress of chronic pulmonary disease to pulmonary hypertension enables us to state that chronic cardiopulmonary disorders are previous to anaphylaxis episodes.

In our adjusted analysis, presence of asthma was associated with mechanical ventilation. COPD and all chronic pulmonary diseases were associated with invasive mechanical ventilation and an increased risk of cardiac arrest. Brown [5] observed that pre-existing lung disease was associated with an increased risk of hypoxia. In the study of Mulla and Simons [9], which was based on coded records of anaphylaxis admissions, an association was found between COPD and invasive mechanical ventilation and long hospital stay, between interstitial respiratory illnesses and invasive mechanical ventilation and death during admission, and between asthma and invasive mechanical ventilation.

Coagulation disorders and fluid-electrolyte imbalance also increased the severity of anaphylaxis episodes and were likely triggered by anaphylaxis episodes. The association between fluid-electrolyte imbalance and poorer prognosis is probably due to the severity of the anaphylaxis episode, since acidosis accounts for almost $60 \%$ of this item in the ICD-9-CM.

Individual coagulation disorders were very heterogeneous, and the only conditions with a notable percentage of cases were defibrination syndrome (17\%), which includes disseminated intravascular coagulation, and other unspecific coagulation disorders $(25 \%)$. Several studies have shown activation of clotting and clot lysis during severe anaphylaxis. The results of a murine study strongly suggest that disseminated intravascular coagulation occurs in systemic anaphylaxis and that platelet-activating factor is the main mediator responsible for the phenomenon [27]. Histamine induces tissue factor expression in human endothelial cells and vascular smooth muscle cells [28], leading to formation of thrombin. In 1980, Smith et al [29] reported that, of 3 patients experiencing anaphylactic shock during controlled hymenoptera challenges, 2 had decreased levels of factors V and VIII, fibrinogen, and high-molecular-weight kininogen [29].

In their study based on 2 databases covering a population with employer-sponsored health insurance and individuals aged $\geq 65$ years, Clark et al [6] found that patients with more severe anaphylaxis (leading to admission) had a higher 
Charlson-Deyo score (modified Charlson comorbidity index) [30,31], a higher number of laboratory/radiology tests performed during the year before admission, or a visit to the emergency department or admission (any cause) during the previous year. Both these findings and ours suggest that more severe anaphylaxis episodes were associated with more severe previous comorbidity.

Markers of severity of anaphylaxis tended to be more frequent in older patients ( $\geq 50$ years). Consequently, the severity of anaphylaxis in older and elderly patients is due not only to the more marked presence of cardiorespiratory diseases or more frequent comorbidity, but also to other age-related factors. Several authors have also reported that older age is an independent risk factor that increases severity of anaphylaxis in their adjusted models [4-7]. One possible explanation for age as an independent risk factor is that the effects of comorbid conditions are more marked in older patients. However, in our study, the interaction between age and respiratory and cardiovascular diseases was not statistically significant (data not shown).

Except for Echinococcus anaphylaxis, our adjusted multivariate analysis did not reveal a major cause of anaphylaxis (eg, food, drugs) that had a higher risk of being associated with a worse course of anaphylaxis. Severe or recurrent anaphylaxis due to Echinococcus can occur if fluid from a cyst is released into a host who has developed IgE from a previous leakage $[32,33]$. Anaphylaxis complicates $10 \%$ of all intraperitoneal ruptures of cysts [34] and is responsible for $20 \%$ of sudden deaths occurring in echinococcosis [32,33]. In our literature review, we were unable to find an explanation for the severity of anaphylaxis in these patients. We can speculate that the sudden and marked presence of Echinococcus antigens in the body increases the severity of anaphylaxis, in much the same way as an intravenous medication does in drug anaphylaxis [35]. It is also possible that other mechanisms of death, such as shock secondary to a severe inflammatory response on peritoneal surfaces, can also play a role in increased severity of anaphylaxis.

It is important to ask whether our findings among hospitalized patients can be extrapolated to the general population. In the strictest sense, we can only state that among patients admitted to hospital, older patients seem to experience more severe anaphylaxis, a finding that has been reported in other studies of mortality and severity of anaphylaxis in various clinical settings (not only in patients admitted to hospital).

In extremely severe cases (fatal cases), the risk factors associated with fatal anaphylaxis include upright posture, uncontrolled asthma, tree nuts, male sex, drug anaphylaxis, African-American ethnicity, and, mainly, older age likely combined with multiple comorbidities [36,37]. In older patients, this risk has traditionally been explained as a reduced capacity to tolerate the effects of hypoxia, hypotension, and arrhythmia. In our study, age older than 50 years, Echinococcus anaphylaxis, and pulmonary circulatory disorders may have contributed to fatal anaphylaxis, whereas arrhythmias, coagulation disorders, and fluid-electrolyte imbalance were probably complications of anaphylaxis that led to death.

In addition to the limitations of secondary clinicaladministrative data based on the $I C D-9-C M$ coding used in epidemiologic studies of anaphylaxis (intermediate positive predictive value and low internal validity) [38] and the limitations of the Elixhauser score (underrecording of relevant items, accuracy of secondary diagnosis, coding errors, and potential financial pressure to capture better remunerated comorbidities) [11], the large number of outcomes used to identify the most severe episodes reported makes it difficult to compare our findings with those from other studies. On the other hand, patients with anaphylaxis managed in the intensive care unit in the database used in this study did not represent all the patients who were attended in this setting during the study period, but only the patients who were discharged from the intensive care unit. Significant results from the smallest age groups related to some of the outcomes (length of stay, use of vasopressor drugs) may be inconsistent given the lower number of patients who had or experienced these outcomes in these age groups.

We provide a comprehensive assessment of the main chronic diseases that can aggravate an anaphylaxis episode. Our findings suggest that respiratory and cardiovascular diseases, other comorbidities, and older age can increase the severity of anaphylaxis episodes. Finally, the severity of anaphylaxis may be associated with the severity of a previous illness.

\section{Acknowledgments}

The authors are grateful to the "Subdirección General del Instituto de Información Sanitaria" for providing the data on which this study is based.

\section{Funding}

The authors declare that no funding was received for the present study.

\section{Conflicts of Interest}

The authors declare that they have no conflicts of interest.

\section{Previous Presentations}

Risk factors associated with cardiac arrest and death in hospitalized patients due to anaphylaxis during the period 19982011. EAACI Congress 2016, Vienna, Austria, June 11-15, 2016.

Severity of anaphylaxis is associated to higher comorbidity. Analysis of hospitalized patients in Spain during 1998-2011. EAACI Congress 2016, Vienna, Austria, June 11-15, 2016.

\section{References}

1. Brown AF, McKinnon D, Chu K. Emergency department anaphylaxis: A review of 142 patients in a single year. J Allergy Clin Immunol. 2001;108:861-6.

2. Pumphrey R. Anaphylaxis: can we tell who is at risk of a fatal reaction? Curr Opin Allergy Clin Immunol. 2004;4:285-90.

3. Pumphrey RS GM. Further fatal allergic reactions to food in the United Kingdom, 1999-2006. J Allergy Clin Immunol. 2007; 119:1018-9.

4. Summers C, Pumphrey RSH, Woods CN, McDowell GM, Pemberton PW, Arkwright PD. Factors predicting anaphylaxis 
to peanuts and tree nuts in patients referred to a specialist center. J Allergy Clin Immunol. 2008;121:631-8.

5. Brown SG. Clinical features and severity grading of anaphylaxis. J Allergy Clin Immunol. 2004;114:371-6.

6. Clark S, Wei W, Rudders SA, Camargo Jr. CA. Risk factors for severe anaphylaxis in patients receiving anaphylaxis treatment in US emergency departments and hospitals. J Allergy Clin Immunol. 2014;134:1125-30.

7. Rueff F, Przybilla B, Bilo MB, Müller U, Scheipl F, Aberer W, Birnbaum J, Bodzenta-Lukaszyk A, Bonifazi F, Bucher C, Campi P, Darsow U, Egger C, Haeberli G, Hawranek T, Körner M, Kucharewicz I, Küchenhoff $H$, Lang R, Quercia O, Reider N, Severino M, Sticherling M, Sturm GJ, Wüthrich B.. Predictors of severe systemic anaphylactic reactions in patients with Hymenoptera venom allergy: importance of baseline serum tryptase - a study of the European Academy of Allergology and Clinical Immunology Interest Group on Insect Venom Hypersensitivity. J Allergy Clin Immunol. 2009;124:1047-54.

8. Lee S, Hess EP, Nestler DM, Bellamkonda Athmaram VR, Bellolio MF, Decker WW, Li JT, Hagan J B ,Manivannan V, Vukov SC, Campbell RL. Antihypertensive medication use is associated with increased organ system involvement and hospitalization in emergency department patients with anaphylaxis. J Allergy Clin Immunol. 2013;131:1103-8.

9. Mulla ZD, Simons FE. Concomitant chronic pulmonary diseases and their association with hospital outcomes in patients with anaphylaxis and other allergic conditions: a cohort study. BMJ Open. 2013;3:10.1136/bmjopen-2013-003197.

10. Nassiri M, Babina M, Dolle S, Edenharter G, Rueff F, Worm M. Ramipril and metoprolol intake aggravate human and murine anaphylaxis: evidence for direct mast cell priming. J Allergy Clin Immunol. 2015;135:491-9.

11. Elixhauser A, Steiner C, Harris DR, Coffey RM. Comorbidity measures for use with administrative data. Med Care. 1998:36:8-27.

12. Ministerio de Sanidad y Consumo, International Classification of Diseases 9th Revision Clinical Modification; 2010. Available at: http://www msc es/estadEstudios/estadisticas/ normalizacion/ clasifEnferm/instrucNorma htm. Accessed March 22, 2011.

13. Harduar-Morano L, Simon MR, Watkins S, Blackmore C. Algorithm for the diagnosis of anaphylaxis and its validation using population-based data on emergency department visits for anaphylaxis in Florida. J Allergy Clin Immunol. 2010;126:98-104.e4.

14. Sampson HA, Muñoz-Furlong $A$, Campbell RL, Adkinson NF Jr, Bock SA, Branum A, Brown SG, Camargo CA Jr, Cydulka R, Galli SJ, Gidudu J, Gruchalla RS, Harlor AD Jr, Hepner DL, Lewis LM, Lieberman PL, Metcalfe DD, O'Connor R, Muraro A, Rudman A, Schmitt C, Scherrer D, Simons FE, Thomas S, Wood JP, Decker WW. Second symposium on the definition and management of anaphylaxis: summary report - second National Institute of Allergy and Infectious Diseases/Food Allergy and Anaphylaxis Network symposium. J Allergy Clin Immunol. 2006;117:391-7.

15. van Walraven $C$, Austin PC, Jennings $A$, Quan $H$, Forster AJ. A modification of the Elixhauser comorbidity measures into a point system for hospital death using administrative data. Med Care. 2009;47:626-33.
16. ARHQ. ARHQ: creation of format library for comorbidity software (version 3.5). Available at: http://www.hcupus.

17. ahrq.gov/toolssoftware/comorbidity/comformat2005-010405.txt. Accessed January 17, 2016.

18. Quan H, Li B, Couris CM, Fushimi K, Graham P, Hider P, Januel JM, Sundararajan V. Updating and validating the Charlson comorbidity index and score for risk adjustment in hospital discharge abstracts using data from 6 countries. Am J Epidemiol. 2011;173(6):676-82.

19. Pearson or Hosmer-Lemeshow goodness-of-fit test. Stata Base Reference Manual, Release 14. 14th ed. College Station: Stata Press Publication; 2015. p. 639-47.

20. Bang JH, Hwang SH, Lee EJ, Kim Y. The predictability of claimdata-based comorbidity-adjusted models could be improved by using medication data. BMC Med Inform Decis Mak. 2013;13:128. doi: 10.1186/1472-6947-13-128

21. Yoshihara $H$, Yoneoka D. Incidental dural tear in spine surgery: analysis of a nationwide database. Eur Spine J. 2014;23:38994.

22. Triggiani M, Patella V, Staiano RI, Granata F, Marone G. Allergy and the cardiovascular system. Clin Exp Immunol. 2008;153 Suppl 1:7-11.

23. James PA, Oparil S, Carter BL, Cushman WC, DennisonHimmelfarb C, Handler J, Lackland DT, LeFevre ML, MacKenzie TD, Ogedegbe O, Smith SC, Jr, Svetkey LP, Taler SJ, Townsend RR, Wright JT, Jr, Narva AS, Ortiz E. 2014 evidence-based guideline for the management of high blood pressure in adults: report from the panel members appointed to the Eighth Joint National Committee (JNC 8). JAMA. 2014;311(5):507-20.

24. Ryan TJ, Anderson JL, Antman EM, Braniff BA, Brooks NH, Califf RM, Hillis LD, Hiratzka LF, Rapaport E, Riegel BJ, Russell RO, Smith E Jr, Weaver WD. ACC/AHA guidelines for the management of patients with acute myocardial infarction. A report of the American College of Cardiology/American Heart Association Task Force on Practice Guidelines (Committee on Management of Acute Myocardial Infarction). J Am Coll Cardiol. 1996;28:1328-428.

25. Lieberman P, Simons FE. Anaphylaxis and cardiovascular disease: therapeutic dilemmas. Clin Exp Allergy. 2015;45:1288-95

26. Lang DM, Alpern MB, Visintainer PF, Smith ST. Elevated risk of anaphylactoid reaction from radiographic contrast media is associated with both beta-blocker exposure and cardiovascular disorders. Arch Intern Med. 1993:153:2033-40.

27. Antman EM, Loscalzo J. ST-Segment Elevation Myocardial Infarction. In: Kasper DL, Fauci AS, Hauser SL, Longo DL, Jameson JL, Loscalzo J, editors. Harrison's. Principles of Internal Medicine. 19th ed. New York: Mc Graw Hill Education; 2015. p. 1599-610.

28. Choi IH, Ha TY, Lee DG, Park JS, Lee JH, Park YM, Lee HK. Occurrence of disseminated intravascular coagulation (DIC) in active systemic anaphylaxis: role of platelet-activating factor. Clin Exp Immunol. 1995;100:390-4.

29. Steffel J, Akhmedov A, Greutert H, Luscher TF, Tanner FC. Histamine induces tissue factor expression: implications for acute coronary syndromes. Circulation. 2005;112:341-9.

30. Smith PL, Kagey-Sobotka A, Bleecker ER, Traystman R, Kaplan AP, Gralnick H, Valentine MD, Permutt $S$, Lichtenstein LM. Physiologic manifestations of human anaphylaxis. J Clin Invest. 1980;66:1072-80. 
31. Charlson ME, Pompei P, Ales KL, MacKenzie CR. A new method of classifying prognostic comorbidity in longitudinal studies: development and validation. J Chronic Dis. 1987;40: 373-83.

32. Deyo RA, Cherkin DC, Ciol MA. Adapting a clinical comorbidity index for use with ICD-9-CM administrative databases. J Clin Epidemiol. 1992;45:613-9.

33. Minciullo PL, Cascio A, David A, Pernice LM, Calapai G, Gangemi S. Anaphylaxis caused by helminths: review of the literature. Eur Rev Med Pharmacol Sci. 2012;16(11):1513-8.

34. Sanei B, Hashemi SM, Mahmoudieh M. Anaphylactic shock caused by nonruptured hydatid cyst of the liver. J Gastrointest Surg. 2008;12:2243-5.

35. Nunnari G, Pinzone MR, Gruttadauria S, Celesia BM, Madeddu G, Malaguarnera G, Pavone, Cappellani A, Cacopardo B. Hepatic echinococcosis: clinical and therapeutic aspects. World J Gastroenterol. 2012;18:1448-58.

36. Pumphrey RS. Fatal anaphylaxis in the UK, 1992-2001. Novartis Found Symp. 2004;257:116-28; discussion 128-32, 157-60, 276-85.

37. Tejedor-Alonso MA, Moro-Moro M1, Múgica-García MV. Epidemiology of Anaphylaxis: Contributions from the last 10 Years. J Investig Allergol Clin Immunol. 2015;25:163-75.
38. Mullins RJ, Wainstein BK, Barnes EH, Liew WK, Campbell DE. Increases in anaphylaxis fatalities in Australia from 1997 to 2013. Clin Exp Allergy. 2016;46:1099-110.

39. Walsh KE, Cutrona SL, Foy $S$, Baker MA, Forrow $S$, Shoaibi A, Pawloski PA, Conroy M, Fine AM, Nigrovic LE , Selvam N, Selvan MS, Cooper WO, Andrade S. Validation of anaphylaxis in the Food and Drug Administration's Mini-Sentinel. Pharmacoepidemiol Drug Saf. 2013;22:1205-13. Manuscript received July 26, 2016; accepted for
publication January 30, 2017 .

\section{Miguel A Tejedor-Alonso}

Allergy Unit, Hospital Universitario Fundación Alcorcón, Madrid

Avda Budapest 1

28922 Alcorcón, Madrid

Spain

E-mail:m914674227@telefonica.net

matejedor@fhalcorcon.es 